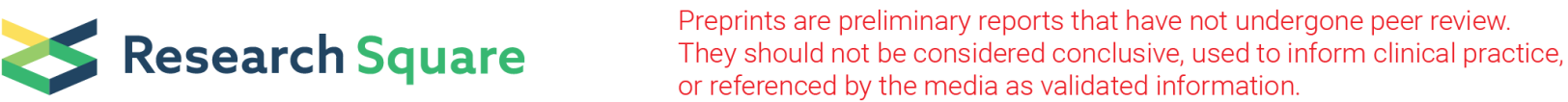

\section{The Use Of Intrathecal Morphine For Acute Postoparative Pain In Lower Limb Arthroplasty Surgery: A Survey Of Practice At An Academic Hospital.}

Mpumelelo Sibanyoni ( $\nabla$ sibanyonimpume6@gmail.com )

Chris Hani Baragwanath Academic Hospital https://orcid.org/0000-0002-8361-9188

Ntombiyethu Biyase

Wits University: University of the Witwatersrand https://orcid.org/0000-0002-2120-0162

Palesa Motshabi Chakane

Wits University: University of the Witwatersrand https://orcid.org/0000-0001-9990-6336

\section{Research Article}

Keywords: Intrathecal morphine, spinal anaesthesia, hip arthroplasty, knee arthroplasty

Posted Date: February 17th, 2022

DOI: https://doi.org/10.21203/rs.3.rs-902587/v2

License: (c) (i) This work is licensed under a Creative Commons Attribution 4.0 International License.

Read Full License 


\section{Abstract}

Background and purpose of the study: Intrathecal morphine (ITM) provides optimal postoperative analgesia in patients who are scheduled for total knee and hip operation with spinal anaesthesia. However, the ideal dose at which maximal analgesic effect occurs with minimal side effects is not known. This study aimed to describe the use of two doses of ITM, and side effect profile in patients undergoing elective hip and knee arthroplasty.

Methods: This was a prospective, descriptive, and contextual study conducted on patients who had total hip and knee replacement at Chris Hani Baragwanath Academic Hospital from 1 September to 30 November 2020. The sample size consisted of 66 patients who were 18 years and older, American Society of Anaesthesiology (ASA) classification 1-3, patients who had received either 100 mcg or 150 mcg ITM dose under spinal anaesthesia and sent to the ward postoperatively. Visual Analogue Scale (VAS) score was used to assess pain in the first 24 hours, consumption of rescue analgesia and reported side effects were documented.

Results: There was no relationship between age, weight, ASA classification or type of surgery and VAS score classification groups. Patients who received $100 \mathrm{mcg}$ ITM had a higher median VAS pain score 2 (1-5) compared to those who received $150 \mathrm{mcg}$ ITM 1 (0-2), $p=0.01$. The need for rescue analgesia between the two groups was marginally less in the $150 \mathrm{mcg}$ ITM group $(p=0.098)$. There was no difference in the rate of side effects between the $100 \mathrm{mcg}$ ITM group [12 (41\%)] and the $150 \mathrm{mcg}$ ITM group [17 (59\%)], $p=0.92$. Rescue analgesia was marginally different between groups, $p=0.09$. There were no real differences in the VAS pain scores between the total knee and total hip surgeries. None of the patients experienced clinically significant respiratory depression.

Conclusion: The 150mcg ITM dose provided good analgesic effects with longer duration of action and comparable side effect profile to the $100 \mathrm{mcg}$ ITM dose. This dose was not associated with development of respiratory depression can therefore be administered safely to patients who are discharged to the ward postoperatively in a resource constraint environment.

\section{Background}

In 1979 Wang demonstrated the efficacy of intrathecal morphine (ITM) for postoperative analgesia in patients with genitourinary cancer, since then ITM has become widely used (1). Morphine was the first opioid to be approved by Food and Drug Administration for its use in neuraxial anaesthesia $(1,2)$. The added benefits of using ITM are that it is simple to administer, it is not associated with increase in blood loss during surgery and has longer duration of action (3). It is cost effective as it leads to early mobilization and decrease hospital stay $(2,4,5)$.

Morphine is hydrophilic and its binds high affinity to the central nervous system opioids receptors. This results in its prolonged presence within the water-soluble cerebrospinal fluid resultings in prolonged duration of action up to 24 hours and its cause of delayed respiratory depression $(1,6,7)$. Intrathecal 
morphine also causes other side effects such as postoperative nausea and vomiting, pruritus, and urinary retention $(1,8)$. Long duration of analgesia has made ITM a suitable option for postoperative analgesia in patients who are scheduled for total knee and hip operation with spinal anaesthesia (3).

The international consensus on anaesthesia-related outcome after surgery group has recommended the use of neuraxial anaesthesia during joint replacement (9). Many studies have endeavoured to define or determine the low dose of ITM with excellent analgesic effects and minimal or no side-effects (8). The dose of $100 \mathrm{mcg}-200 \mathrm{mcg}$ ITM has been shown to provide a good balance between analgesia and sideeffects $(10,11)$. Most patients that are scheduled for hip and knee arthroplasty are elderly, Intrathecal morphine has the advantage of reducing the stress response and metabolic demand during surgery and anaesthesia in the elderly (12). There is contradicting evidence of where patients should be recovered post-surgery with ITM $(1,10)$.

We sought to assess the analgesic effect of two doses of ITM, describe the perioperative outcomes ITM related complications/side effects and to assess the safety of managing these patients in a normal ward in a resource constraint environment of arguably the largest hospital on the continent, Chris Hani Baragwanath Academic Hospital (13).

\section{Methods}

The study was conducted in the Arthroplasty unit and the Department of Anaesthesiology at Chris Hani Baragwanath Academic Hospital., affiliated with the Faculty of Health Sciences of the University of the Witwatersrand. Approval to conduct the study was obtained from the Human Research Ethics Committee and the University of the Witwatersrand and other relevant authorities. The study followed a prospective, descriptive, and contextual research design. This study aimed to describe the use of ITM for perioperative pain in patients undergoing hip and knee arthroplasty who were discharged to the ward postoperatively and the side effect profile associated with ITM injection use.

The study population included patients 18 years and older, American Society of Anaesthesiology (ASA) physical status 1-3 scheduled for elective knee and hip arthroplasty who received ITM injection and spinal anaesthesia and sent to the ward postoperatively. Written informed consent was obtained from all patients included in the study. Patients were excluded if they were having obstructive sleep apnoea, respiratory diseases, ASA physical status 4 and above, had receive general anaesthetic and intrathecal morphine, and patient records which were illegible. The study period was from 1 September to 30 November 2020.

After the procedure, patients were monitored in the recovery room then discharged to the ward. In the ward patients were monitored for postoperative pain, pruritus, nausea and vomiting and respiratory depression for the first 24 hours. Respiratory depression was defined as respiratory rate of less than 10 breaths per minutes or oxygen saturation of less than $90 \%$. Patients were treated for the side effects if they experience any. 
Pain scores were evaluated using a visual analogue scale from 0 to 10 with 0 indicating no pain and 10 severe pain. Rescue analgesia and time from ITM administration were also documented. The rescue analgesia regimen included paracetamol $1 \mathrm{~g}$, tramadol hydrochloride dose $50-100 \mathrm{mg}$, and pethidine 50$100 \mathrm{mg}$. The pain free hours were divided into 3-hour periods and the median VAS pain scores within the first 24-hours were determined for each group.

\section{STATISTICAL ANALYSIS}

Sixty-six patients participated in the study. The categorical variables were described using frequencies and percentages. We used the chi-square test for significance of association between categorical variables and the intrathecal morphine dose (outcome). The Fisher's exact test was used to find the association between categorical variables (age, ASA and type of surgery) and VAS pain scores. Continuous variables were described using median and interquartile ranges since they were not normally distributed according to the Shapiro-Wilk test. The relationship between continuous variables and intrathecal morphine dose (outcome) was assessed using the Mann-Whitney test. Weight and VAS pain scores association was assessed using the Kruskal Wallis test which is a non-parametric alternative to ANOVA.

\section{Results}

Sixty-six patients received spinal anaesthesia with ITM injection. Of the 66 patients, 29 (44\%) received $100 \mathrm{mcg}$ ITM dose and 37 (56\%) received $150 \mathrm{mcg}$ ITM dose. From the $100 \mathrm{mcg}$ ITM dose group, 11 (38\%) were male and 18 (62\%) were female (Table 1). From the $150 \mathrm{mcg}$ ITM dose group 19 (51\%) were male and $18(49 \%)$ were female. Majority of the patients were 50 years old and older. The median (IQR) weight of the patients was $75(65-79) \mathrm{kg}$ in the $100 \mathrm{mcg}$ ITM group and $73(65-80) \mathrm{kg}$ in the $150 \mathrm{mcg}$ ITM group (Table 1).

In total, 8 (12.12\%) patients were classified as ASA I, 53 (80\%) ASA II and 5 (8\%) were ASA III. There were $48(73 \%)$ who underwent hip arthroplasty patients compared to $18(27 \%)$ who were underwent knee arthroplasty in the study. Within the hip arthroplasty group 23 (48\%) had $100 \mathrm{mcg}$ IT morphine dose while only $6(33 \%)$ of the knee arthroplasty received $100 \mathrm{mcg}$ IT morphine. Twenty-five (52\%) patients received $150 \mathrm{mcg}$ IT morphine from the hip arthroplasty group and 12 (67\%) patients from the knee arthroplasty group. The overall bupivacaine dose administered was median (IQR) was 14 (13 - 14.5), $13(12-14)$ in the $100 \mathrm{mcg}$ ITM group and $14(14-15)$ in the 150 mcg ITM group. 
Table 1

Demographic and baseline characteristics

\begin{tabular}{|c|c|c|c|c|}
\hline \multicolumn{2}{|l|}{ Variable } & \multirow{2}{*}{$\begin{array}{l}\text { Overall } n=66 \\
30(45)\end{array}$} & \multirow{2}{*}{$\begin{array}{l}100 \text { mcg ITM n = } 29 \\
11(37)\end{array}$} & \multirow{2}{*}{$\begin{array}{l}150 \text { mcg ITM n = } 37 \\
19(63)\end{array}$} \\
\hline Gender & Male & & & \\
\hline & Female & $36(55)$ & $18(50)$ & $18(50)$ \\
\hline \multirow[t]{5}{*}{ Age in years } & $<40$ & $7(11)$ & $0(0.0)$ & $7(100)$ \\
\hline & $40-49$ & $5(8)$ & $1(20)$ & $4(80)$ \\
\hline & $50-59$ & $19(29)$ & $10(53)$ & $9(47)$ \\
\hline & $60-69$ & $23(31)$ & $9(39)$ & $14(61)$ \\
\hline & $70+$ & $12(18)$ & $9(75)$ & $3(25)$ \\
\hline \multicolumn{2}{|c|}{ Weight [Median (IQR)] } & $74.5(65-80)$ & $75(65-79)$ & $73(65-80)$ \\
\hline \multirow[t]{3}{*}{ ASA } & I & $8(12)$ & $3(38)$ & $5(62)$ \\
\hline & $\|$ & $53(80)$ & $25(47)$ & $28(53)$ \\
\hline & III & $5(7.58)$ & $1(20)$ & $4(80)$ \\
\hline \multirow[t]{2}{*}{ Surgery } & THR & $48(73)$ & $23(48)$ & $25(52)$ \\
\hline & TKR & $18(27)$ & $6(33)$ & $12(67)$ \\
\hline Bupivacaine & Median (IQR) & $14(13-14.5)$ & $13(12-14)$ & $14(14-15)$ \\
\hline
\end{tabular}

There was no relationship between age, weight, ASA classification or type of surgery between VAS score classification groups (Table 2).

A total of $29(44 \%)$ patients did not have side effects in the study. There was no difference in the rate of side effects between the 100 mcg ITM group [12 (41\%)] and the 150 mcg ITM group [17 (59\%)], p = 0.92 (Table 3). Pruritus was not dose dependant as 11 (50\%) patients in each ITM group had pruritus with a total of $22(33 \%)$ overall. The overall number of patients who developed nausea and vomiting was 5 (8\%) with 2 (40\%) patients in the $100 \mathrm{mcg}$ ITM group and $3(60 \%)$ in the $150 \mathrm{mcg}$ ITM group. Patients who had both pruritus, nausea and vomiting accounted for only 10 (15\%) patients of which $4(40 \%)$ were in the $100 \mathrm{mcg}$ ITM group and $6(60 \%)$ in the $150 \mathrm{mcg}$ ITM group. None of the patients experienced clinically significant respiratory depression. 
Table 2

Comparison between VAS pain scores and basic characteristics categories

\begin{tabular}{|c|c|c|c|c|c|c|}
\hline \multirow[t]{2}{*}{ Variable } & & \multicolumn{4}{|c|}{ VAS pain scores $\mathrm{n}(\%)$} & \multirow{2}{*}{$\begin{array}{l}\mathrm{p}- \\
\text { value }\end{array}$} \\
\hline & & None & Mild 1 - 3 & $\begin{array}{l}\text { Moderate } 4 \text { - } \\
6\end{array}$ & Severe $>6$ & \\
\hline \multirow{5}{*}{$\begin{array}{l}\text { Age in } \\
\text { years }\end{array}$} & $<40$ & $3(43)$ & $2(29)$ & $1(14)$ & $1(14)$ & \multirow[t]{5}{*}{0.45} \\
\hline & $40-49$ & $2(40)$ & $1(20)$ & $2(40)$ & $0(0)$ & \\
\hline & $50-59$ & $4(21)$ & $10(53)$ & $4(21)$ & $1(5)$ & \\
\hline & $60-69$ & $4(17)$ & $14(61)$ & $1(4)$ & $4(18)$ & \\
\hline & $70+$ & $2(17)$ & $6(50)$ & $2(17)$ & $2(17)$ & \\
\hline Weight & $\begin{array}{l}\text { Median } \\
\text { (IQR) }\end{array}$ & $\begin{array}{l}73(60- \\
85)\end{array}$ & $\begin{array}{l}70(65- \\
80)\end{array}$ & $73(69-79)$ & $\begin{array}{l}75(75- \\
81)\end{array}$ & 0.48 \\
\hline \multirow[t]{3}{*}{ ASA } & I & $1(12)$ & $5(63)$ & $1(12.5)$ & $1(12.5)$ & \multirow[t]{3}{*}{0.61} \\
\hline & II & $13(25)$ & $26(49)$ & $9(17)$ & $5(9)$ & \\
\hline & III & $1(20)$ & $2(40)$ & $0(0)$ & $2(40)$ & \\
\hline \multirow[t]{2}{*}{ Surgery } & THR & $11(23)$ & $24(50)$ & $9(19)$ & $4(8)$ & \multirow[t]{2}{*}{0.34} \\
\hline & TKR & $4(22)$ & $9(50)$ & $1(6)$ & $4(22)$ & \\
\hline
\end{tabular}

There was a significant difference in median (IQR) VAS pain scores between the $100 \mathrm{mcg}$ ITM and the 150 mcg ITM groups [2 $(1-5)$ and $1(0-2)$, respectively], $p=0.01$. The need for rescue analgesia between the $100 \mathrm{mcg}$ and $150 \mathrm{mcg}$ ITM groups was marginally different $(p=0.098)$. Of note is that 19 (29\%) patients did not require rescue analgesia. The use of phenylephrine (PEP) and ephedrine was not different between groups. 
Table 3

Comparison of post-operative outcomes by ITM dose

\begin{tabular}{|c|c|c|c|c|c|}
\hline \multicolumn{2}{|l|}{ Variable } & \multirow{2}{*}{$\begin{array}{l}\text { Overall } n= \\
66 \\
29(44)\end{array}$} & \multirow{2}{*}{$\begin{array}{l}100 \mathrm{mcg} \text { ITM } \\
\mathbf{n}=29\end{array}$} & \multirow{2}{*}{ 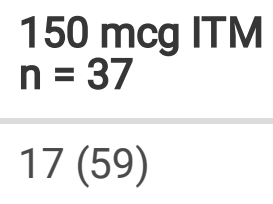 } & \multirow{2}{*}{$\begin{array}{l}\begin{array}{l}\text { p- } \\
\text { value }\end{array} \\
0.92\end{array}$} \\
\hline Side & None & & & & \\
\hline & Pruritus & $22(33)$ & $11(50)$ & $11(50)$ & \\
\hline & Nausea \& Vomiting & $5(8)$ & $2(40)$ & $3(60)$ & \\
\hline & Both & $10(15)$ & $4(40)$ & $6(60)$ & \\
\hline \multirow[t]{2}{*}{ PEP } & Yes & $21(32)$ & $10(48)$ & $11(53)$ & \multirow[t]{2}{*}{0.68} \\
\hline & No & $45(68)$ & $19(42)$ & $26(58)$ & \\
\hline \multirow[t]{2}{*}{ Ephedrine } & Yes & $7(11)$ & $4(57)$ & $3(43)$ & \multirow[t]{2}{*}{0.46} \\
\hline & No & $59(89)$ & $25(42)$ & $34(58)$ & \\
\hline \multirow{6}{*}{$\begin{array}{l}\text { Rescue } \\
\text { analgesia }\end{array}$} & Paracetamol & $3(5)$ & $3(100)$ & $0(0)$ & \multirow[t]{6}{*}{0.098} \\
\hline & Tramadol hydrochloride & $21(32)$ & $11(52)$ & $10(48)$ & \\
\hline & Pethidine & $15(23)$ & $5(33)$ & $10(67)$ & \\
\hline & $\begin{array}{l}\text { Paracetamol \& Tramadol } \\
\text { hydrochloride }\end{array}$ & $6(9)$ & $4(45)$ & $2(33)$ & \\
\hline & Paracetamol \& Pethidine & $2(3)$ & $1(50)$ & $1(50)$ & \\
\hline & None & $19(29)$ & $5(26)$ & $14(74)$ & \\
\hline \multicolumn{2}{|c|}{ Pain free time $(\min )$ [Median (IQR)] } & $\begin{array}{l}720(540- \\
1110)\end{array}$ & $\begin{array}{l}675(540- \\
785)\end{array}$ & $\begin{array}{l}720(550- \\
1440)\end{array}$ & 0.31 \\
\hline \multicolumn{2}{|c|}{ VAS score Median (IQR) } & $2(1-4)$ & $2(1-5)$ & $1(0-2)$ & 0.01 \\
\hline
\end{tabular}

The patients who had received $100 \mathrm{mcg}$ of ITM had a relatively higher VAS pain score within the first 24 hours when compared to those who received $150 \mathrm{mcg}$ ITM after adjusting for the time it took to start feeling pain (Figure 1).

Although the side effect profile was statistically not different (Figure 2), the percentage of patients who had both pruritus, nausea and vomiting as side effects was high in the $150 \mathrm{mcg}$ ITM group compared to 100 mcg ITM group.

There were no real differences in the VAS pain scores between the two surgeries as observed from the line graphs which cross multiple times in the illustration (Figure 3). 
Median (IQR) VAS pain scores were lower in the 150 mcg ITM group [1(0 - 2)] compared to the $100 \mathrm{mcg}$ ITM group [2 (1 - 5)], $p=0.01$. Many studies have been done to find the suitable dose of intrathecal morphine or defining the dose of intrathecal morphine in patients undergoing hip and knee arthroplasty which provide good analgesia and less side effects $(3,5,7,8,10,11,14-16)$. In our setting, the importance is in finding a suitable dose with analgesic effects, and fewer side effects to allow for our patients to be cared for in a normal ward. Dose-response studies demonstrated that ITM have an analgesic efficacy ceiling and the optimal dose of ITM is $0.075-0.15 \mathrm{mg}(2)$.

Although there was no significant difference in pain free time between the two groups, there was a marginal difference in need for rescue analgesia with those in the 150 mcg ITM needing less. Importantly no cases of respiratory depression were reported, not only making the $150 \mathrm{mcg}$ ITM superior in pain relief but equivalent statistically in side effect profile.

The 150 mcg ITM group had a high percentage of patients who had nausea and vomiting compared to the 100 mcg ITM group. However, the percentage of patients who had both pruritis, nausea and vomiting as side effects was higher in the $150 \mathrm{mcg}$ ITM group compared to $100 \mathrm{mcg}$ ITM group. Previous studies have demonstrated that higher doses of ITM were associated with higher incidences of nausea and vomiting $(5,8,9,16)$. The incidence and severity of nausea and vomiting is a major concern following the use of ITM particularly as orthopaedic surgery on it own is an independent risk factor of nausea and vomiting $(3,5,10,17)$.

Hassett et.al demonstrated that patients who received $100 \mathrm{mcg}$ ITM had poor pain management compared to the patients who received $200 \mathrm{mcg}$ ITM and $300 \mathrm{mcg}$ ITM (7). The median time to request first rescue analgesia was lower in $100 \mathrm{mcg}$ IT morphine which was 442 minutes compare to $200 \mathrm{mcg}$ IT morphine 607 minutes and 300 mcg IT morphine 857 minutes. In our study we reported median time to rescue of $675 \mathrm{~min}$ in the $100 \mathrm{mcg}$ ITM group compared to $720 \mathrm{~min}$ in the $150 \mathrm{mcg}$ ITM group.

In this study we found no real differences in the VAS pain scores between the total hip and total knee replacement, $p=0.34$. A previous study had reported differences in pain scores between these groups(18). The requirement for rescue analgesia (intravenous morphine) was similarly found to be reduced in patients who have total hip replacement compare to total knee replacement (14).

In this study, there were no cases that were reported to have experienced respiratory depression. Some studies use intravenous opioids or patient - controlled analgesia with opioids as rescue analgesia which can also cause respiratory depression $(2,19,20)$. The incidence of respiratory depression has been found to be as low as $3 \%$ using a doses $0.2 \mathrm{mg}$ to $0.8 \mathrm{mg}$ ITM in one study (21). We postulate that this may be the contributing factor. Delayed respiratory depression occurs at $6-12$ hours and may persist up to 24 hours (22-24).

The median bupivacaine was $13 \mathrm{mg}$ in the $100 \mathrm{mcg}$ ITM and $14 \mathrm{mg}$ in the $150 \mathrm{mcg}$ ITM group respectively and use of phenylephrine and ephedrine were not significantly different, $p=0.68$ and $p=$ 
0.46 respectively. Majority of patients were $\geq 50$ years old with no differences in baseline characteristics. More had total hip replacement than total knee replacement.

\section{Limitations}

The study is contextual with a small sample size. The results cannot therefore be generalised. It however presents good data for use in similar circumstances such as low to medium income countries with constraint resources.

\section{Conclusion}

A $150 \mathrm{mcg}$ ITM dose can be used with good postoperative analgesic effects, with longer duration of analgesia and reduced postoperative requirement of rescue analgesia compared to $100 \mathrm{mcg}$ in patients scheduled for total hip and knee arthroplasty. Although nausea and vomiting, pruritis were reported at this dose, they were not significantly different and were successfully treated. Most importantly, at this dose, the most dreadful side effect of delayed respiratory depression was not reported. Thus, patients who received $150 \mathrm{mcg}$ ITM were safe in a non-high dependency area such as a normal ward postoperatively provided anticipated side effects can be monitored and managed timeously.

\section{Abbreviations}

ITM: Intrathecal morphine; VAS: Visual analogue scale; PEP: Phenylephrine; ASA: American society of anaesthesiology; THR: Total hip replacement; TKR: Total knee replacement; NV: Nausea and vomiting

\section{Declarations}

\section{Ethics approval and consent to participate}

This study was approved by the Human Research Ethics committee (medical) of the University of the Witwatersrand with the approval number M200670. The patient provided written consent. All methods were carried out in accordance with Declaration of Helsinki and South African Good Clinical Practice Guideline.

\section{Consent for publication}

Not applicable

\section{Availability of data and materials}

The data is available from the corresponding author on request.

\section{Competing interest}


No competing interest.

\section{Funding}

No funds were needed in the study.

\section{Authors contributions}

MS, NB and PMC design, analysed the data and wrote the manuscript. All authors read and approved the final manuscript.

\section{Acknowledgement}

Not applicable.

\section{References}

1. DeSousa KA, Chandran RJWJA. Intrathecal morphine for postoperative analgesia: current trends. world Journal of Anesthesiology. 2014;3(3):191-202. https://doi:10.5313/wja.v3.i3.191

2. Sultan P, Gutierrez MC, Carvalho BJD. Neuraxial morphine and respiratory depression. 2011;71(14):1807-19. https://doi:10.2165/11596250-000000000-0000

3. Gehling M, Luesebrink T, Kulka P, Tryba MJEJoA. The effective duration of analgesia after intrathecal morphine in patients without additional opioid analgesia: a randomized double-blind multicentre study on orthopaedic patients. European Journal of Anaesthesiology. 2009;26(8):683-8.

https://doi:10.1097/EJA.0b013e328329b045

4. Mugabure BB. An Update on Neuraxial Opioid Induced Pruritus Prevention. Journal of Anesthesia \& Critical Care: Open Access. 2016;6(2):00226. https://doi:10.15406/jaccoa.2016.06.00226

5. Hess SR, Lahaye LA, Waligora AC, Sima AP, Jiranek WA, Golladay GJJEJoOS, et al. Safety and sideeffect profile of intrathecal morphine in a diverse patient population undergoing total knee and hip arthroplasty. European Journal of Orthopeadic Surgery \& Traumatology. 2019;29(1):125-9. https://doi:10.1007/s00590-018-2293-9

6. Ruan X. Drug-related side effects of long-term intrathecal morphine therapy. Pain Physician. 2007;10(2):357.

7. Hassett P, Ansari B, Gnanamoorthy P, Kinirons B, Laffey JG. Determination of the efficacy and sideeffect profile of lower doses of intrathecal morphine in patients undergoing total knee arthroplasty. BMC Anesthesiology. 2008;8(1):5. https://doi:10.1186/1471-2253-8-5

8. Gehling M, Tryba M. Risks and side-effects of intrathecal morphine combined with spinal anaesthesia: a meta-analysis. Journal of the Association of Anesthesia of Great Britain and Ireland. 2009;64(6):643- 
9. Pathonsamit C, Onklin I, Hongku N, Chaiyakit PJAt. Randomized Double-Blind Controlled Trial Comparing $0.2 \mathrm{mg}, 0.1 \mathrm{mg}$, and No Intrathecal Morphine Combined With Periarticular Injection for Unilateral Total Knee Arthroplasty. Arthroplsty Today. 2021;7:253-9.

https://doi:org/10.1016/j.artd.2020.11.008

10. Slappendel R, Weber EW, Dirksen R, Gielen MJ, van Limbeek J, Analgesia. Optimization of the dose of intrathecal morphine in total hip surgery: a dose-finding study. J Anesthesia

1999;88(4):822-6. https://doi:10.1097/00000539-199904000-00026

11. Murphy P, Stack D, Kinirons B, Laffey JJA, Analgesia. Optimizing the dose of intrathecal morphine in older patients undergoing hip arthroplasty. Anesthesia and analgesia. 2003;97(6):1709-15. https://doi:10.1213/01.ane.0000089965.75585.0d

12. Kwan A, Lee B, Brake T. Intrathecal morphine for post-operative analgesia in patients with fractured hips. Hong Kong Medical Journal. 1997;3:250-5.

13. Hospital CHBA. 2020 [Available from: http://www.chrishanibaragwanathhospital.co.za.

14. Rathmell JP, Pino CA, Taylor R, Patrin T, Viani BA. Intrathecal morphine for postoperative analgesia: a randomized, controlled, dose-ranging study after hip and knee arthroplasty. Anesthesia and analgesia. 2003;97(5):1452-7. https://doi:10.1213/01.ane.0000083374.44039.9e

15. Bowrey S, Hamer J, Bowler I, Symonds C, Hall J. A comparison of 0.2 and $0.5 \mathrm{mg}$ intrathecal morphine for postoperative analgesia after total knee replacement. Anaesthesia. 2005;60:449-52. https://doi:10.1111/j.1365-2044.2005.04174.x

16. Rojas A, Hernández M, Vidal P, Balkenhol M, Opazo M, Riquelme M, et al. Low dose intrathecal morphine for hip arthroplasty. Revista Chilena de Anestesia. 2020;49:153-60. https://doi:org/10.25237/revchilanestv49n04-11

17. Cheah JW, Sing DC, Hansen EN, Aleshi P, Vail TP. Does intrathecal morphine in spinal anesthesia have a role in modern multimodal analgesia for primary total joint arthroplasty? The Journal of arthroplasty. 2018;33(6):1693-8. https://doi:10.1016/j.arth.2018.01.016

18. Salmon P, Hall GM, Peerbhoy D, Shenkin A, Parker C, Rehabilitation. Recovery from hip and knee arthroplasty: Patients' perspective on pain, function, quality of life, and well-being up to 6 months postoperatively. Archives of Physical Medicine Rehabilitation 2001;82(3):360-6. https://doi:10.1053/apmr.2001.21522

19. Ko S, Goldstein DH, VanDenKerkhof EG. Definitions of "respiratory depression" with intrathecal morphine postoperative analgesia: a review of the literature. Canadian Journal of Anaesthesia. 
20. Cole PJ, Craske DA, Wheatley RG. Efficacy and respiratory effects of low-dose spinal morphine for postoperative analgesia following knee arthroplasty. BJA: British Journal of Anaesthesia. 2000;85(2):2337. https://doi:10.1093/bja/85.2.233

21. Gwirtz KH, Young JV, Byers RS, Alley C, Levin K, Walker SG, et al. The safety and efficacy of intrathecal opioid analgesia for acute postoperative pain: seven years' experience with 5969 surgical patients at Indiana University Hospital. Anesthesia and analgesia 1999;88(3):599-604.

https://doi:10.1097/00000539-199903000-00026

22. Bailey PL, Rhondeau S, Schafer PG, Lu JK, Timmins BS, Foster W, et al. Dose-response pharmacology of intrathecal morphine in human volunteers. The Journal of the American Society of Anesthesiologists

1993;79(1):49-59. https://doi:10.1097/00000542-199307000-00010

23. Kafer ER, Brown JT, Scott D, Findlay JWA, Butz RF, Teeple E, et al. BIPHASIC DEPRESSION OF THE MINUTE VENTILATION RESPONSE TO CO 2FOLLOWING EPIDURAL MORPHINE. Anesthesiology. 1982;57(3):A482-A. https://doi:10.1097/00000542-198209001-00482

24. Abboud TK, Moore M, Zhu J, Murakawa K, Minehart M, Longhitano M, et al. Epidural butorphanol or morphine for the relief of post-cesarean section pain: ventilatory responses to carbon dioxide. Anesthesia and analgesia. 1987;66(9):887-93.

\section{Figures}




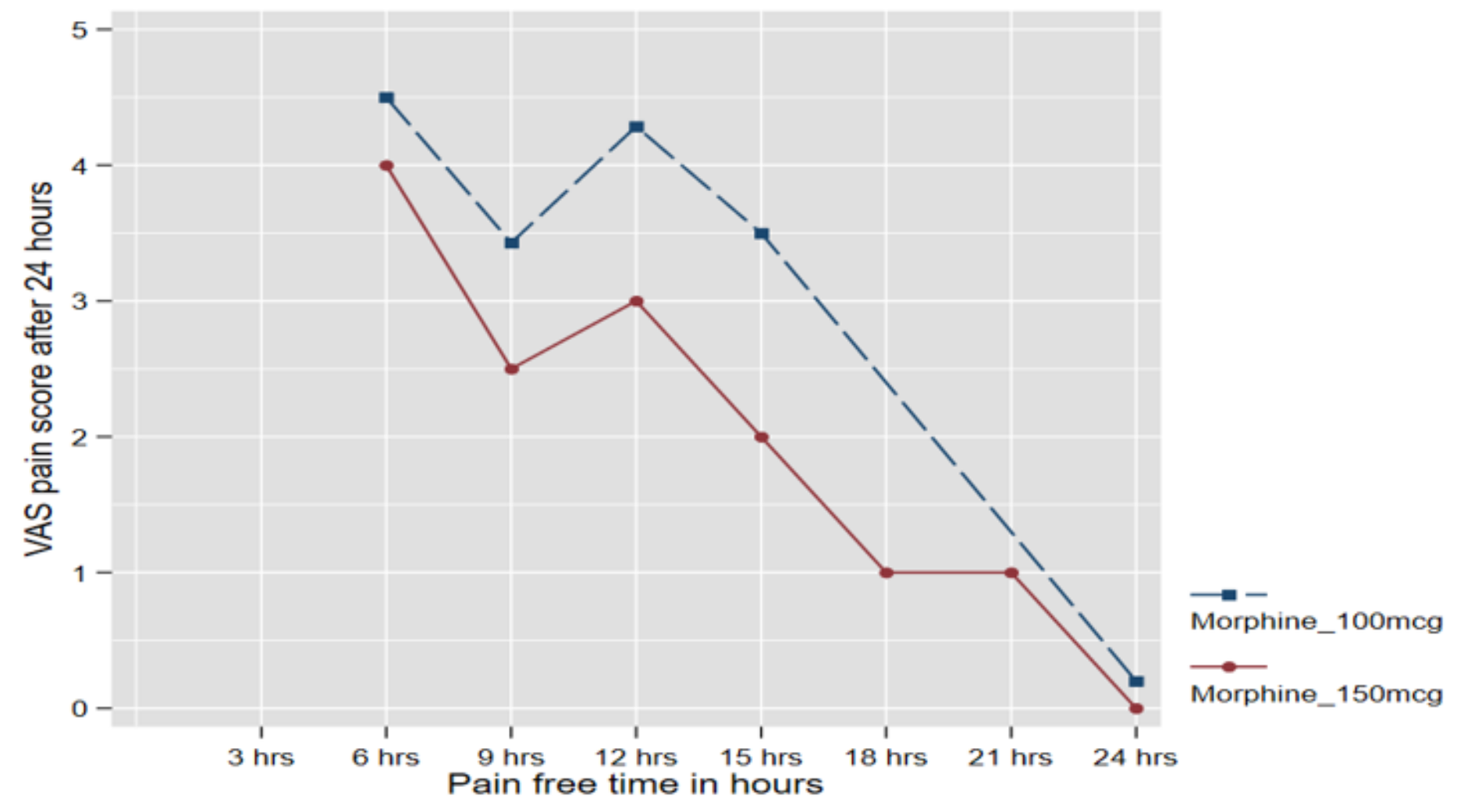

Figure 1

VAS pain scores for patients given 100mcg ITM group and the 150mcg ITM group adjusted for the number of hours it took for the patient to start feeling pain within the first 24 hours.

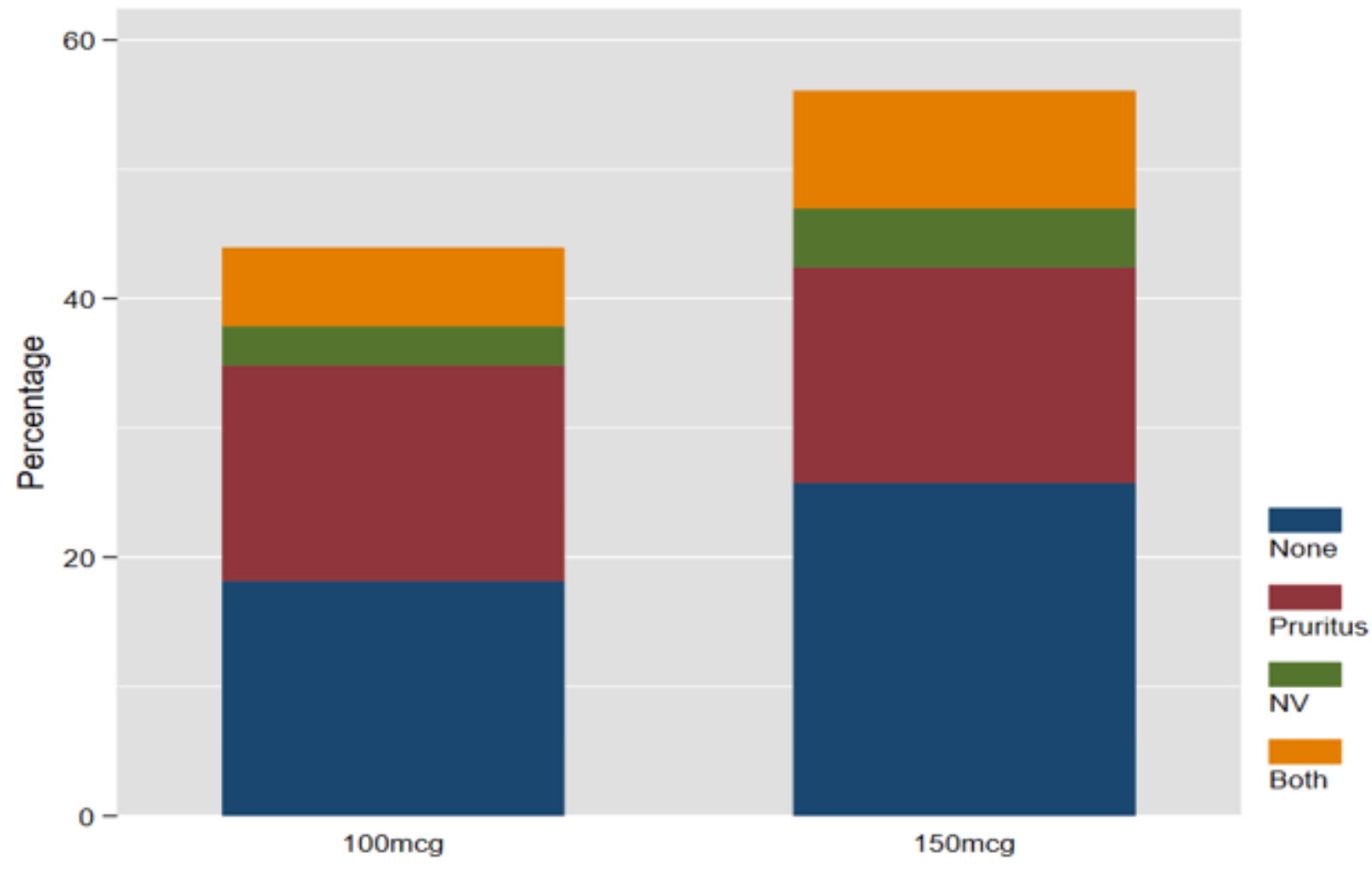


Figure 2

Comparison of side effect profiles between groups

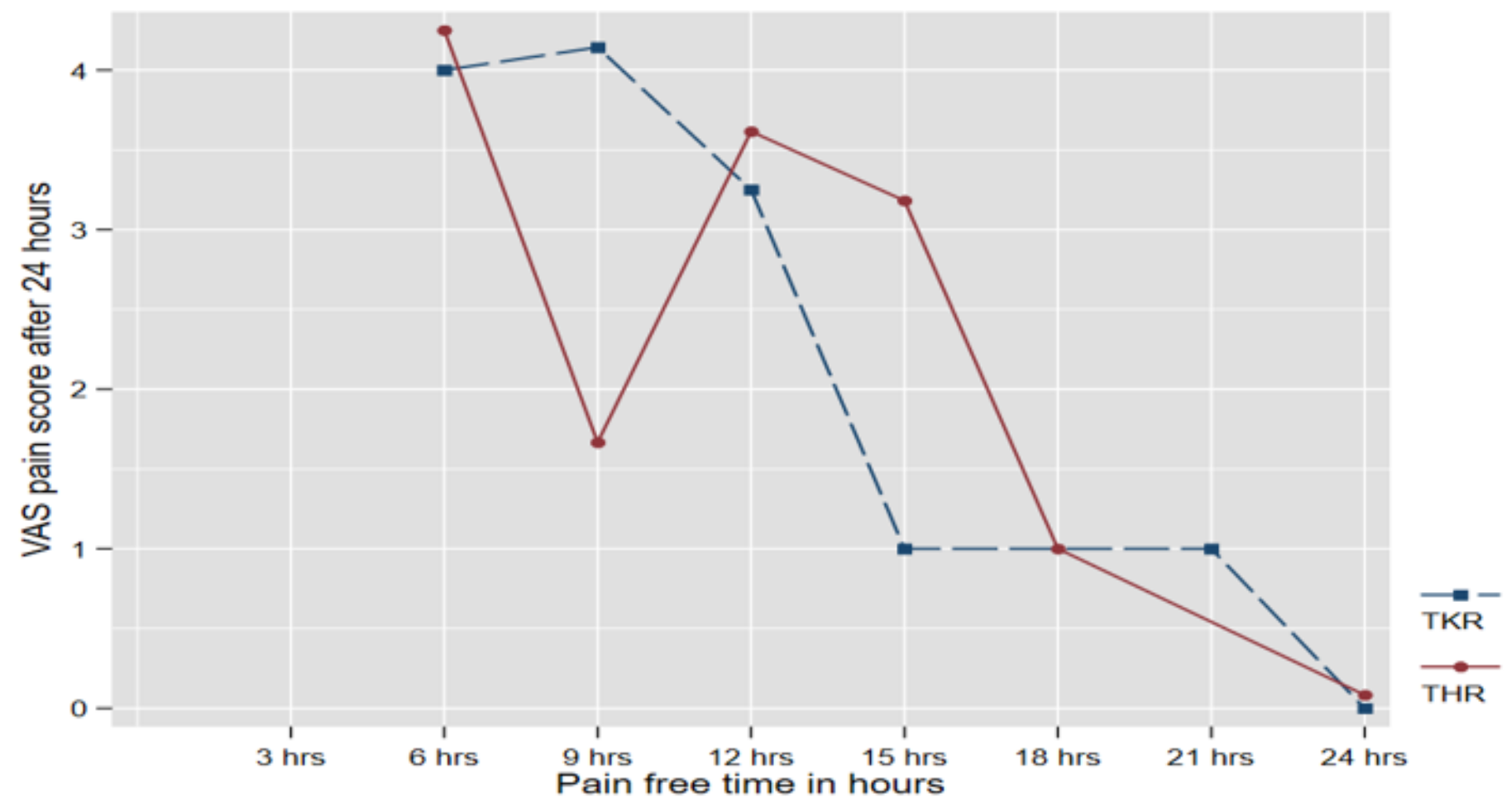

Figure 3

VAS pain score by type of surgery (TKR and THR) adjusted for the pain free hours. 